\title{
Effect of Thermal Annealing on Mid-Infrared Transmission in Semiconductor Alloy-Core Glass-Cladded Fibers
}

\author{
Mustafa Ordu ${ }^{1,2}$ (1) - Jicheng Guo ${ }^{3,4} \cdot$ Ahmet E. Akosman $^{5} \cdot$ Shyamsunder Erramilli $^{3,6,7} \cdot$ Siddharth Ramachandran ${ }^{3,7,8}$. \\ Soumendra N. Basu ${ }^{1,3,7}$
}

Received: 4 November 2019 / Accepted: 29 January 2020 / Published online: 28 February 2020

(c) Donghua University, Shanghai, China 2020

\begin{abstract}
We report a study investigating the effects of thermal annealing on the optical properties of Si-Ge alloy-core silica-cladded fibers. Low temperature fiber draw was performed with a laboratory-made draw tower at $1760{ }^{\circ} \mathrm{C}$ that minimizes impurity diffusion from cladding to the core. As a post-drawing process, $\mathrm{Si}-\mathrm{Ge}$ core fibers were annealed in a box furnace to alter the core structure. Microstructural and optical properties of fibers were investigated, and transmission losses were measured as $28 \mathrm{~dB} / \mathrm{cm}$ at $6.1 \mu \mathrm{m}$. Numerical studies were performed to analyze the experimental results and to find the optimum structure for low loss semiconductor-core glass-cladded fibers.
\end{abstract}

Keywords Semiconductor-core fibers $\cdot$ Mid-IR fibers $\cdot$ Thermal annealing $\cdot \mathrm{Si}-\mathrm{Ge}$ alloys

\section{Introduction}

Transmission in mid-infrared (IR) spectral region has numerous applications in spectrometry, biomedical surgery and remote chemical sensing owing to the vibrational

Electronic supplementary material The online version of this article (https://doi.org/10.1007/s42765-020-00030-2) contains supplementary material, which is available to authorized users.

Mustafa Ordu

ordu@unam.bilkent.edu.tr

1 Department of Mechanical Engineering, Boston University, Boston, MA 02215, USA

2 UNAM-National Nanotechnology Research Center and Institute of Materials Science and Nanotechnology, Bilkent University, Ankara 06800, Turkey

3 Division of Materials Science and Engineering, Boston University, Brookline, MA 02446, USA

4 Argonne National Laboratory, Lemont, IL 60439, USA

5 School of Engineering, Roger Williams University, Bristol, RI 02809, USA

6 Department of Physics, Boston University, Boston, MA 02215, USA

7 Photonics Center, Boston University, Boston, MA 02215, USA

8 Department of Electrical and Computer Engineering, Boston University, Boston, MA 02215, USA fingerprints of the various molecules in the targeted spectral region [1-3]. The opaqueness of conventional silica fibers above $3 \mu \mathrm{m}$ gives rise to the necessity of alternative materials for the mid-IR spectrum. Material groups such as fluorides, chalcogenides, heavy metal oxides and halide crystals have been investigated for nontoxic, easy-to-fabricate and low transmission loss fibers in the mid-IR spectrum [4]. The promising low transmission losses in the targeted region make them suitable materials, however mechanical and chemical problems such as devitrification at room temperature, water absorption and photodarkening under visible light limit their practical usage [5]. Semiconductors such as $\mathrm{Si}$ and $\mathrm{Ge}$ have wide transmission windows in the mid-IR along with low bulk transmission losses and they possess mechanical and chemical stabilities making them suitable candidates for fiber materials. Various methods have been proposed to draw semiconductor fibers such as high-pressure chemical vapor deposition (HP-CVD) [6], powder-in-tube [7] and rod-in-tube [8]. Among these methods, only rodin-tube is amenable for long fiber drawing, and it allows control over fiber parameters such as outer diameter (OD), inner diameter (ID), core/cladding ratio, and polymer coating. To date, various semiconductors have been proposed as core materials to draw semiconductor-core glass-cladded fibers with rod-in-tube method and various structural and optical characterizations were performed with the drawn fibers [9-12]. 
The alloying of different semiconductors can combine the individual properties of fibers and can produce fibers with tailored optical properties such as transmission windows and refractive indices. Also it can form graded-index fibers that have not been reported in the mid-IR spectrum yet. Several studies were aimed to develop semiconductor alloycore fibers with various elements and compositions [13-17]. Recently, Si and Ge were used to form alloy-core fibers, however, the structural inhomogeneity of the alloy-core fibers causes high transmission losses, requiring post-fiber drawing processes [14, 15]. Laser recrystallization [14] and thermal annealing [15] were performed to increase the homogeneity of the fiber core and to improve the optical performances.

In this paper, the effect of thermal annealing to the optical and structural properties of Si-Ge alloy-core silica glass-cladded fibers were investigated. Fibers were drawn in a laboratory-made mini draw tower at $1760{ }^{\circ} \mathrm{C}$ by rod-intube method that is amenable for long fiber drawing. Fibers were characterized in the mid-IR spectrum with a Quantum Cascade Laser (QCL) at $6.1 \mu \mathrm{m}$. Fibers were further annealed in a box-type furnace with controlled heating rate in air to increase the core uniformity that affects the optical performance of the fibers. The transmission loss of high $\mathrm{Ge}$ percentage (9.5 at\%) alloy fiber was $28 \mathrm{~dB} / \mathrm{cm}$ at $6.1 \mu \mathrm{m}$. Additional numerical studies were performed to investigate the optimum structure for $\mathrm{Si}-\mathrm{Ge}$ alloy-core fibers.

\section{Experimental Details}

An $8 \mathrm{~mm}$ long, $1.9 \mathrm{~mm}$ OD Ge rod was core-drilled from a $10 \times 10 \times 50 \mathrm{~mm}^{3}$ monocrystalline Ge sample of $99.999 \%$ purity (Lattice Materials LLC, Bozeman, MT, USA). A Si tube with $2 \mathrm{~mm}$ ID, $3 \mathrm{~mm}$ OD and $10 \mathrm{~mm}$ length was manufactured from a $10 \times 10 \times 50 \mathrm{~mm}^{3}$ monocrystalline Si sample of $99.999 \%$ purity (Lattice Materials LLC, Bozeman, MT, USA). One side of the silica tube was not drilled and a cuplike structure was formed to cover the Ge rod in the preform. During the heating of the preform to reach the drawing temperature, the Ge rod melts earlier than the Si tube since the melting point of $\mathrm{Ge}$ is much lower than $\mathrm{Si}(\mathrm{Ge}$ melts at $938^{\circ} \mathrm{C}$ and $\mathrm{Si}$ melts at $1414{ }^{\circ} \mathrm{C}$.). By forming this structure, molten Ge was kept away longer times from the cladding that may increase the diffusion of oxygen. The Ge rod-Si tube combination was placed inside a silica tube (Technical Glass Products, Inc., Painesville, OH, USA) with $3 \mathrm{~mm}$ ID and $9 \mathrm{~mm}$ OD. Additional silica tube with $10 \mathrm{~mm}$ ID and $15 \mathrm{~mm}$ OD was added concentrically to increase the ratio of cladding with respect to the core. The semiconductor core was sealed with silica rods from the top and bottom sides to prevent oxidation at the elevated drawing temperatures. The rod-intube method was selected to draw $\mathrm{Si}-\mathrm{Ge}$ alloy-core fibers. A more detailed explanation of the drawing can be found in the literature $[9,18]$. Fibers were drawn in a laboratory-made mini draw tower at $1760{ }^{\circ} \mathrm{C}$ in the Department of Mechanical Engineering at Boston University, USA. The typical draw temperature of silica glasses is around $2000{ }^{\circ} \mathrm{C}$, but since $1760{ }^{\circ} \mathrm{C}$ is higher than the softening temperature of silica and melting points of $\mathrm{Si}$ and $\mathrm{Ge}$, fibers can be successfully drawn at this temperature. The fibers were then annealed to adjust the core structure with a box furnace (Thermo Scientific, Waltham, MA, USA) under normal atmospheric conditions.

Microstructural characterization of the Si-Ge alloy-core silica-cladding fiber was carried out by scanning electron microscopy (SEM)-based energy dispersive x-ray (EDX, Zeiss Supra 55P, Jena, Germany). EDX dot maps of each element and composition profiles across the core-cladding interface were obtained both before and after the post-draw annealing.

\section{Results and Discussion}

\section{Microstructure of the Fibers}

The cross-section image of the fiber can be seen in Fig. 1 a. The core diameter of the fiber is $27 \mu \mathrm{m}$ and cladding diameter is $245 \mu \mathrm{m}$. Figure 1b-d show dot maps of the fiber's cross-section for different elements, indicating the elemental segregation at multiple locations, respectively. This is due to the nucleation at multiple locations during the solidification of the molten alloy core. The formation of Si-rich solid grains occurs at the nucleation sites, and the remaining liquid becomes Ge-rich. A more detailed elemental composition through the core and cladding was obtained by EDX line scan across the core as shown in Fig. 1a, and the result can be seen in Fig. 1e. The atomic percentage of the elements at two particular regions (region A and B; Fig. 1a) that exhibit visual contrast differences in the SEM image, were calculated. Region A had 77.6 at\% Si and 19.4 at\% Ge, while Region B had 91.3 at\% Si and 5.7 at\% Ge. Both regions had approximately 3 at $\% \mathrm{O}$ content.

\section{Post-draw Annealing}

The elemental segregation was not controlled during the fiber draw since the cooling is a rapid process. In order to improve the core uniformity, drawn fibers were annealed and several recipes were used to find the best core structure. After performing different recipes, a multi-step cooling procedure with a hold at a temperature between the solidus and liquidus lines of the alloy composition was found to be the optimum recipe to create a uniform fiber core. Between these lines, the alloy-core is a mixture of solid and liquid $\mathrm{Si}-\mathrm{Ge}$ with different elemental compositions. By dwelling, the diffusion between the grains can improve the uniformity of fiber-core. After heating the 

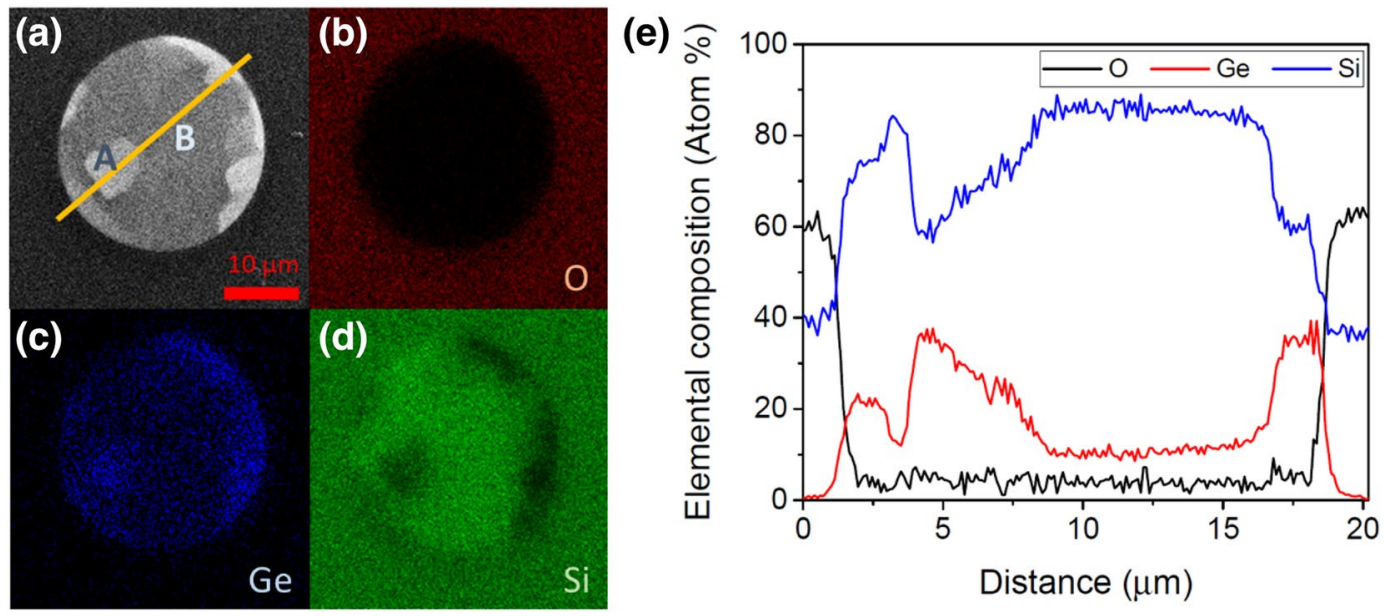

Fig. 1 a SEM micrograph of the core region. EDX elemental dot maps of fiber elements: b O, c Ge and d Si. e Composition profile of the selected line across the fiber core in $\mathbf{a}$

as-drawn fiber to $1465{ }^{\circ} \mathrm{C}$, where the core is completely molten, the sample was kept at this condition for $6 \mathrm{~min}$ (i.e. the minimum dwelling time set by the box furnace). The fiber was cooled to $1350{ }^{\circ} \mathrm{C}$, which is between the liquidus and solidus temperature of the alloy composition with $15^{\circ} \mathrm{C} / \mathrm{min}$ cooling rate, and held at $1350{ }^{\circ} \mathrm{C}$ for $6 \mathrm{~min}$. Later, the fiber was slowly cooled with $2{ }^{\circ} \mathrm{C} / \mathrm{min}$ to $900{ }^{\circ} \mathrm{C}$ after it was removed from the furnace to air-cool to room temperature. Figure 2a-d shows an SEM micrograph of the fiber cross-section along with the $\mathrm{O}, \mathrm{Ge}$ and $\mathrm{Si}$ dot maps. The images clearly indicate that the uniformity of the alloy-core increased, and the core turned into a step-index (SI) structure. Furthermore, Fig. 2e shows the composition profile across the fiber core-cladding interface, reinforcing the evidence of the uniformity in the core. The oxygen presence remains same suggesting the effect of annealing on the diffusion of oxygen from cladding to the core is minimal. Similar to the previously characterized fiber in "Microstructure of the Fibers" section, regions A and B were selected on the fiber core (Fig. 2a), and the atomic percentage of $\mathrm{Si}$ and Ge were calculated. Region A had 87.5 at\% $\mathrm{Si}$ and 9.5 at\% $\mathrm{Ge}$, and region $\mathrm{B}$ has 87.4 at\% $\mathrm{Si}$ and 9.6 at\% Ge. Both regions preserved the oxygen content, and it was found approximately 3 at\%. Thus, this fiber can be characterized as a Si-Ge SI alloy-core fiber. Furthermore, several other recipes of post drawing annealing of the $\mathrm{Si}-\mathrm{Ge}$ alloy core fibers are discussed in the supplementary materials.

\section{Optical Characterization}

Optical characterization of the $\mathrm{Si}-\mathrm{Ge}$ alloy-core fibers was performed with a QCL (Daylight Solutions, CA, USA) at a single wavelength (i.e. $6.1 \mu \mathrm{m}$ ) for a robust measurement
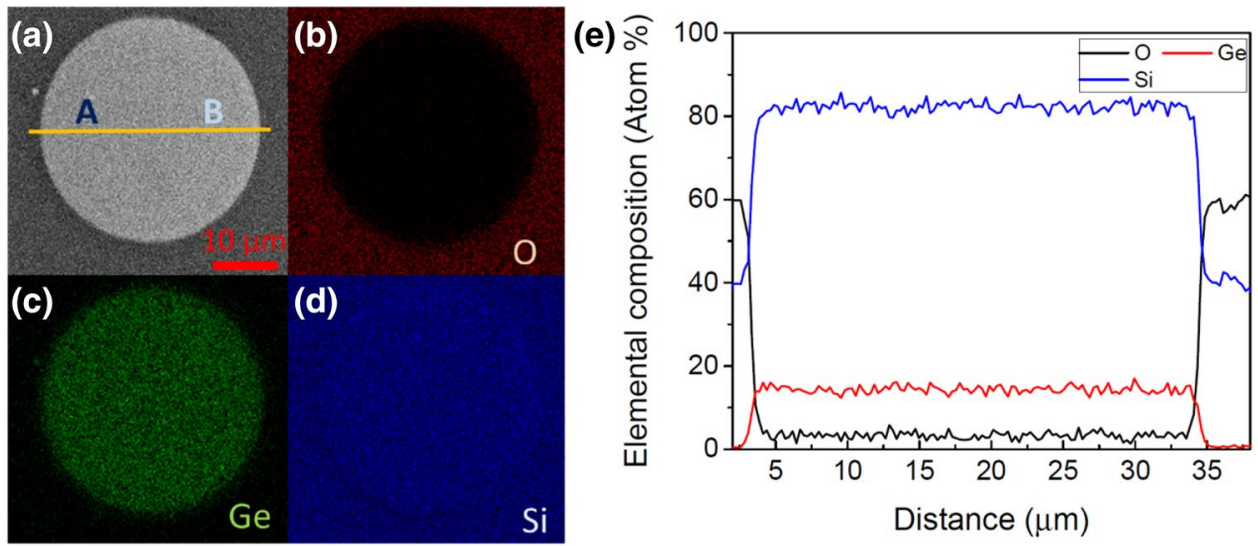

Fig. 2 SEM and EDX images of the fiber after the thermal annealing. a SEM micrograph of the core. Elemental dot maps of b O, $\mathbf{c}$ Ge and $\mathbf{d}$ Si. e Composition profile of the selected line across the core-cladding interface in a 
and a reliable comparison with other similarly made fibers. Output light of the fiber was collected with a mercury cadmium telluride (MCT) detector and appropriate glass absorption filters were used to prevent saturation of the detector. A more detailed explanation of the optical setup can be found in our previous work [11]. The optical transmission losses of the $\mathrm{Si}-\mathrm{Ge}$ SI fiber were calculated by the standard cutback method, and three fiber lengths were used; $7.90 \mathrm{~mm}$, $6.60 \mathrm{~mm}$ and $5.42 \mathrm{~mm}$, with the latter two polished down sequentially from the previous length after the optical measurement. The average transmission loss at $6.1 \mu \mathrm{m}$ was found to be $28 \mathrm{~dB} / \mathrm{cm}$. The transmission losses of the non-uniform $\mathrm{Si}-\mathrm{Ge}$ alloy-core fiber was also calculated using the same method, and it was calculated $75 \mathrm{~dB} / \mathrm{cm}$ at $6.1 \mu \mathrm{m}$. Although homogenizing the alloy-core reduced the refractive index variation and noticeably improved the transmission losses $(75-28 \mathrm{~dB} / \mathrm{cm})$, the losses are still more than the Ge-core and $\mathrm{Si}$-core fibers that were drawn with the same setup and method as depicted in Table 1. One of the reasons for the high transmission loss in the Si-Ge SI alloy-core may be due to the presence of numerous cracks that formed in the cladding after the post-drawing annealing. Increasing the dwelling time at temperature above $1100{ }^{\circ} \mathrm{C}$ accelerates the devitrification of silica glasses. Devitrified silica glasses are fragile to mechanical stresses, and easily form cracks that can penetrate to the cores of the fibers. Figure 3 shows the cracks that are formed in the silica cladding of the $\mathrm{Si}-\mathrm{Ge}$ SI fiber as a result of the post-drawing heat treatment. It is possible that some of these cracks may propagate across the core/cladding interface, thereby increasing the transmission losses.

\section{Simulation Results}

The confinement loss of the fabricated $\mathrm{Si}-\mathrm{Ge}$ alloy core fiber with the same geometrical and elemental composition was also numerically calculated through modal analysis using Comsol Multiphysics. Refractive indices of the core and cladding materials were modeled based on the previous studies in the literature $[19,20]$. The simulation was run between the optical wavelengths of $2 \mu \mathrm{m}$ and $14.8 \mu \mathrm{m}$ and the results were shown in Fig. 4 along with the experimental studies. The significant increase of the calculated losses around $10 \mu \mathrm{m}$ is due to the

Table 1 Experimental and/or numerical transmission losses of fibers with different semiconductor cores at $6.1 \mu \mathrm{m}$

\begin{tabular}{llc}
\hline Fiber core & $\begin{array}{l}\text { Core diameter } \\
(\mu \mathrm{m})\end{array}$ & Loss $(\mathrm{dB} / \mathrm{cm})$ \\
\hline $\mathrm{Ge}[11]$ & 40 & 4.6 \\
$\mathrm{Si}$ [25] & 60 & 11.6 \\
$\mathrm{Si}-$ Ge SI (present work) & 32 & 28 \\
$\mathrm{Si}-$ Ge GRIN (simulation) & 32 & 0.21 \\
\hline
\end{tabular}

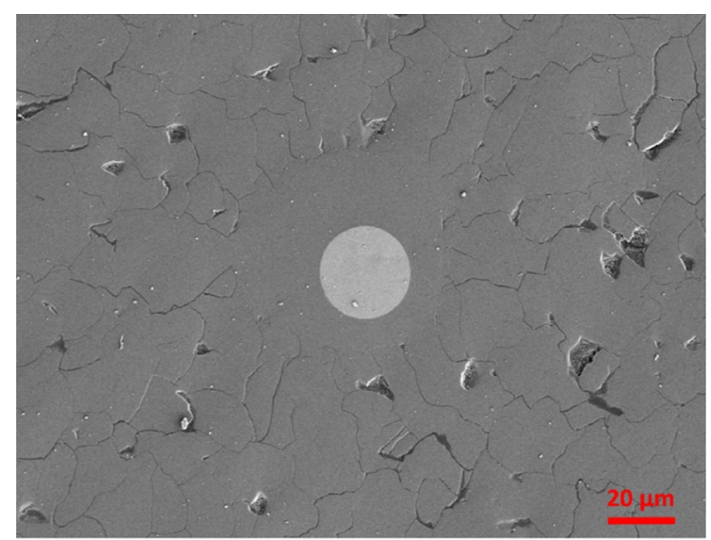

Fig. $3 \mathrm{Si}-\mathrm{Ge}$ alloy-core fiber with the cladding after the post-draw annealing. Cracks in the silica cladding are due to devitrification during the heat treatment

increased absorption of the silica cladding. The impact of the cracks and fabrication based geometrical differences could be the reasons behind the differences between the numerical and experimental results. The numerical studies include perfect elemental structures without any cracks which leads to minimal confinement losses for the wavelength regime of 4-8 $\mu \mathrm{m}$. The electromagnetic modes can be further manipulated by adding extra inclusions of different alloy composition islands in the core and cladding area to mimic the impact of alloy non-uniformity. This further examination should show a significant increase in the confinement loss and irregularity in the geometrical layout of the electromagnetic mode structure.

\section{Future Prospect}

Although the low drawing temperature limits the impurity and oxygen diffusion from cladding to the core, the large coefficient of viscosity of silica decreases the fiber drawing speed,

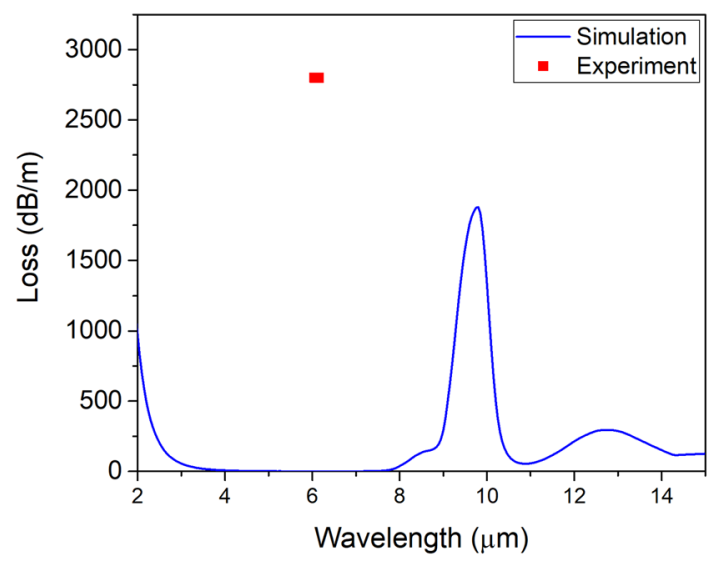

Fig. 4 Comparison of simulation and experimental results of $\mathrm{Si}-\mathrm{Ge}$ alloy-core silica-cladded fibers 
and likely causes an increase in the surface roughness between the core and cladding. The non-uniform elemental segregation and random nucleation at multiple sites of the core are the known reasons behind the high transmission losses with the $\mathrm{Si}-\mathrm{Ge}$ core fibers [14]. On the other hand, the annealed $\mathrm{Si}-\mathrm{Ge}$ SI fibers suffers from devitrification of the silica cladding during the homogenization process even though the homogenization process sharply decreased the transmission losses. Further exploration of post-drawing processes that do not cause structural changes in the cladding could improve the transmission properties of these semiconductor fibers. Recent findings on the necessity of a suitable cladding materials [11, 21] for semiconductor-core fibers can be alternatively solved by modifying the core structure. Graded-index (GRIN) have been used for conventional multimode silica fibers to decrease the modal dispersion [22]. The light can be tightly confined in the core center, and the interaction of the evanescent field and the cladding will be minimized. To compare the losses between an SI and a GRIN fibers, multiple layers of Si-Ge alloys with different compositions were replaced with the Si-Ge SI alloy-core to model a simplified GRIN structure. Figure 5 shows the numerical comparison of the losses for SI and GRIN structures, and the cross-section of the simulated fiber structures. SI fiber has a $32 \mu \mathrm{m}$ alloy-core with a similar composition to the drawn SI fiber and GRIN fiber has a core with five layers. The most outer layer that is $100 \mathrm{at} \% \mathrm{Si}$, has $32 \mu \mathrm{m}$ diameter and the most inner layer that is 100 at $\% \mathrm{Ge}$, has $16 \mu \mathrm{m}$ diameter. The intermediate layers are formed of $\mathrm{Si}-\mathrm{Ge}$ alloys and have the following compositions and diameters: (1) 75 at\% Ge-25 at\% Si with $20 \mu \mathrm{m}$ diameter, (2) 50 at\% Ge-50 at\% Si with $24 \mu \mathrm{m}$ diameter and (3) 25 at\% Ge-75 at $\%$ Si with $28 \mu \mathrm{m}$ diameter. The cladding diameter was kept constant on both of the simulations. Although the SI fiber has lower losses at 3-7 $\mu \mathrm{m}$ region than the GRIN fiber, the transmission losses of the GRIN structure are uniform through the $2-14.8 \mu \mathrm{m}$ region and it is around $30 \mathrm{~dB} / \mathrm{m}$ that is at the same range with the SI fiber. Moreover, the GRIN structure features the suppression of the absorption peak of glasses around $10 \mu \mathrm{m}$ which can be a promising fiber structure for longer wavelength applications such as the optical transmission of $\mathrm{CO}_{2}$ lasers that have emission at 9-11 $\mu \mathrm{m}$ region.

Table 1 shows the experimental transmission losses of different fibers and numerical results of the GRIN Si-Ge alloycore fiber. Fibers in this table were drawn with similar setups and they were optically characterized at the same setup. High transmission losses of Si-Ge SI alloy-core fiber could be due to the following points: devitrification of the cladding glass during the post-draw annealing, oxygen presence in the core and surface roughness at the core-cladding interface. Rapid post-draw annealing can minimize the devitrification of the cladding however the homogenization of the core will be limited (see Supplementary data). Surface roughness could be related to the lower drawing temperature $\left(\sim 1760^{\circ} \mathrm{C}\right)$, but in the same time lower oxygen ratio in the core is attributed to the drawing temperature. This can be seen with the Si-core silica-cladded fiber that has higher losses but lower oxygen presence in the core than the literature [25]. Numerical studies suggest that uniform low transmission losses are possible with the GRIN structure that can extend the application areas of the semiconductor-core fibers. One important application area could be related to the exploitation of the nonlinear properties of the semiconductors since semiconductors such as $\mathrm{Si}$ and $\mathrm{Ge}$ have much higher nonlinearity than the silicabased glasses. Successful experimental demonstrations of various nonlinear properties of semiconductor-core fibers are encouraging for the future studies [23, 24].

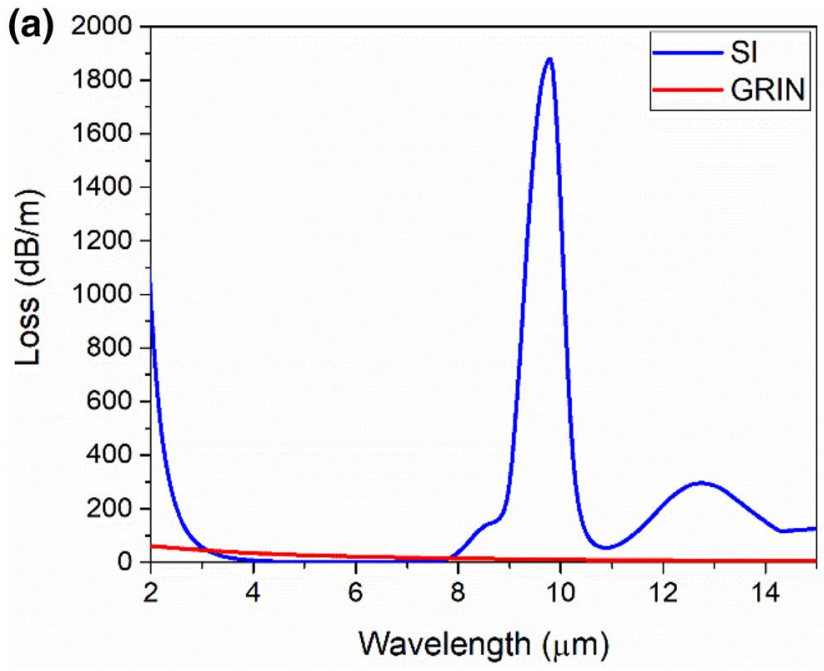

(b)

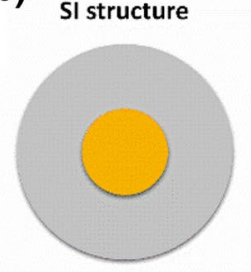

Silicon

Germanium

Si-Ge alloy

Borosilicate glass
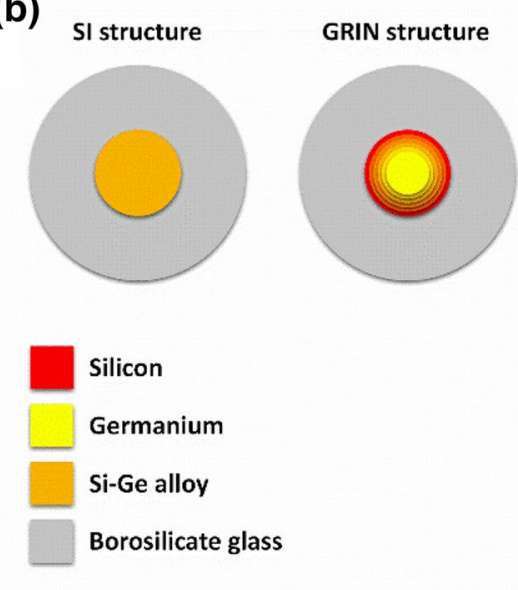

Fig. 5 a Comparison of the transmission losses of Si-Ge SI and GRIN fibers. b The structures of the simulated fibers. GRIN fiber has multiple core layers with increasing $\mathrm{Si} /(\mathrm{Si}+\mathrm{Ge})$ ratio from the core center to the core/cladding interface 


\section{Conclusions}

In conclusion, $\mathrm{Si}-\mathrm{Ge}$ alloy core fibers were successfully drawn and their optical transmission losses were characterized at the mid-IR spectrum. The thermal annealing were applied the fibers to enhance the core structure. SI Si-Ge alloy-core silica glass-cladded fibers were acquired and the transmission losses were found $28 \mathrm{~dB} / \mathrm{cm}$ at $6.1 \mu \mathrm{m}$. The fibers have high Ge content (9.5 at\%) in the core and exhibited good mid-IR transparency. Furthermore, simulation results suggest that GRIN fibers should have better performance than the SI fibers in the mid-IR spectrum. Improvements in the experimental process can be done with better temperature control to form a GRIN structure.

Acknowledgements This project is supported by the National Science Foundation (NSF, Grant number CMMI-1301108, 2013). We would like to thank Y. Gautam for discussion on simulations.

\section{Compliance with Ethical Standards}

Conflict of interest The authors declare no conflicts of interest.

\section{References}

1. Sanghera JS, Aggarwal ID. Active and passive chalcogenide glass optical fibers for IR applications: a review. J Non-Cryst Solids. 1999;256:6-16.

2. Willer U, Saraji M, Khorsandi A, Geiser P, Schade W. Near-and mid-infrared laser monitoring of industrial processes, environment and security applications. Opt Lasers Eng. 2006;44(7):699-710.

3. Artyushenko V, Bocharnikov A, Sakharova T, Usenov I. Midinfrared fiber optics for $1-18 \mu \mathrm{m}$ range: IR-fibers and waveguides for laser power delivery and spectral sensing. Optik Photonik. 2014;9(4):35-9.

4. Tao G, Ebendor-Heidepriem H, Stolyarov AM, Danto S, Badding JV, Fink Y, Ballato J, Abouraddy AF. Infrared fibers. Adv Opt Photonics. 2015;7(2):379-458.

5. Aggarwal ID, Lu G, editors. Fluoride glass fiber optics. London: Academic Press; 2013.

6. Sazio PJ, Amezcua-Correa A, Finlayson CE, Hayes JR, Scheidemantel TJ, Baril NF, Jackson BR, Won DJ, Zhang F, Margine ER, Gopalan V. Microstructured optical fibers as high-pressure microfluidic reactors. Science. 2006;311(5767):1583-6.

7. Scott B, Wang K, Caluori V, Pickrell G. Fabrication of silicon optical fiber. Opt Eng. 2009;48(10):100501.

8. Ballato J, Snitzer E. Fabrication of fibers with high rare-earth concentrations for Faraday isolator applications. Appl Opt. 1995;34(30):6848-54.

9. Ballato J, Hawkins T, Foy P, Stolen R, Kokuoz B, Ellison M, McMillen C, Reppert J, Rao AM, Daw M, Sharma S. Silicon optical fiber. Opt Express. 2008;16(23):18675-83.

10. Ballato J, Hawkins T, Foy P, Morris S, Hon NK, Jalali B, Rice R. Silica-clad crystalline germanium core optical fibers. Opt Lett. 2011;36(5):687-8.

11. Ordu M, Guo J, Tai B, Hong MK, Erramilli S, Ramachandran S, Basu SN. Mid-infrared transmission through germaniumcore borosilicate glass-clad semiconductor fibers. Opt Mater Express. 2017;7(9):3107-15.
12. Peng S, Tang G, Huang K, Qian Q, Chen D, Zhang Q, Yang Z. Crystalline selenium core optical fibers with low optical loss. Opt Mater Express. 2017;7(6):1804-12.

13. Ballato J, Hawkins T, Foy P, McMillen C, Burka L, Reppert J, Podila R, Rao AM, Rice RR. Binary III-V semiconductor core optical fiber. Opt Express. 2010;18(5):4972-9.

14. Coucheron DA, Fokine M, Patil N, Breiby DW, Buset OT, Healy N, Peacock AC, Hawkins T, Jones M, Ballato J, Gibson UJ. Laser recrystallization and inscription of compositional microstructures in crystalline SiGe-core fibres. Nat Commun. 2016;7:13265.

15. Chaudhuri S, Ji X, Huang HT, Day T, Gopalan V, Badding J. Small core SiGe alloy optical fibers by templated deposition. CLEO: applications and technology, OSA; 2017, p. JW2A-69.

16. Song S, Healy N, Svendsen SK, Österberg UL, Covian AC, Liu J, Peacock AC, Ballato J, Laurell F, Fokine M, Gibson UJ. Crystalline $\mathrm{GaSb}$-core optical fibers with room-temperature photoluminescence. Opt Mater Express. 2018;8(6):1435-40.

17. Song S, Lønsethagen K, Laurell F, Hawkins TW, Ballato J, Fokine M, Gibson UJ. Laser restructuring and photoluminescence of glass-clad GaSb/Si-core optical fibres. Nat Commun. 2019; $10(1): 1-7$.

18. Ordu M, Guo J, Tai B, Bird J, Ramachandran S, Basu S. Processing and optical properties of Ge-core fibers. Ceram Mater Energy Appl VI. 2017;37(6):85.

19. Humlíček J, Röseler A, Zettler T, Kekoua MG, Khoutsishvili EV. Infrared refractive index of germanium-silicon alloy crystals. Appl Opt. 1992;31(1):90-4.

20. Kischkat J, Peters S, Gruska B, Semtsiv M, Chashnikova M, Klinkmüller M, Fedosenko O, Machulik S, Aleksandrova A, Monastyrskyi G, Flores Y. Mid-infrared optical properties of thin films of aluminum oxide, titanium dioxide, silicon dioxide, aluminum nitride, and silicon nitride. Appl Opt. 2012;51(28):6789-98.

21. Morris S, Hawkins T, Foy P, Ballato J, Martin SW, Rice R. Cladding glass development for semiconductor core optical fibers. Int J Appl Glass Sci. 2012;3(2):144-53.

22. Senior JM, Jamro MY. Optical fiber communications: principles and practice. 2nd ed. London: Pearson Education; 2009.

23. Ordu M, Guo J, Ng Pack G, Shah P, Ramachandran S, Hong MK, Ziegler LD, Basu SN, Erramilli S. Nonlinear optics in germanium mid-infrared fiber material: detuning oscillations in femtosecond mid-infrared spectroscopy. AIP Adv. 2017;7(9):095125.

24. Peacock AC, Campling J, Runge AF, Ren H, Shen L, Aktas O, Horak P, Healy N, Gibson UJ, Ballato J. Wavelength conversion and supercontinuum generation in silicon optical fibers. IEEE $J$ Select Top Quantum Electron. 2017;24(3):1-9.

25. Ordu M. Fabrication and characterization of semiconductor core optical fibers for mid-infrared transmission, Doctoral dissertation. Boston University; 2018.

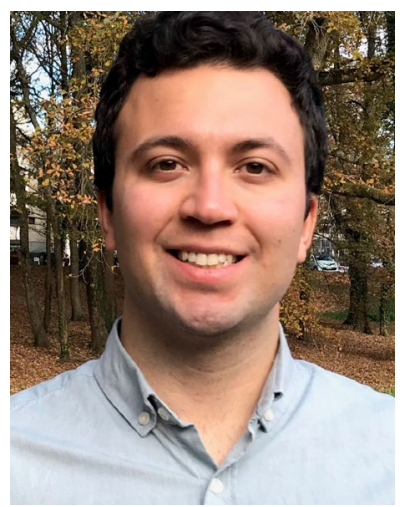

Mustafa Ordu is a principal investigator in UNAM-National Nanotechnology Research Center and Institute of Materials Science and Nanotechnology at Bilkent University, Turkey. He received a B.S. and an M.S. degree in Mechanical engineering from Istanbul Technical University, Turkey and Tohoku University, Japan, respectively. He obtained his Ph.D. degree in Mechanical Engineering from Boston University in 2018. He worked as a postdoctoral 
researcher at XLIM Research Institute in Limoges, France before joining Bilkent University. His research interests focus on semiconductorcore glass fibers and hollow-core photonic crystal fibers mainly for applications in infrared optics.

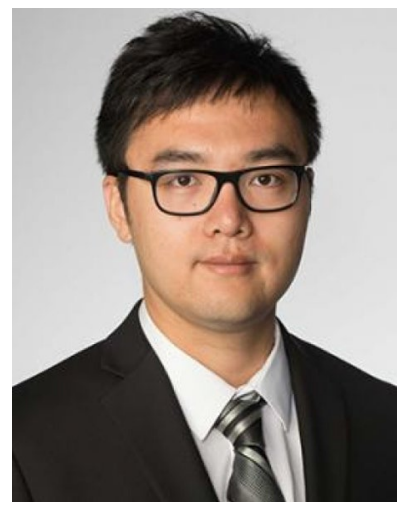

Dr. Jicheng Guo is a postdoctoral researcher of the Chemical and Fuel Cycle Technologies Division at Argonne National Laboratory. He received his $\mathrm{Ph} . \mathrm{D}$. in Materials Science and Engineering from Boston University. He specializes in molten salt chemistry, materials characterization and electrochemistry. Dr. Guo has more than 5 years experiences in electrochemistry for energy storage and conversion, materials characterization for semiconductor optical fibers and heat transfer/mechanical deformation modeling. Dr. Guo's current research focuses on using high energy X-ray diffraction to characterize liquid/glass materials for various applications.

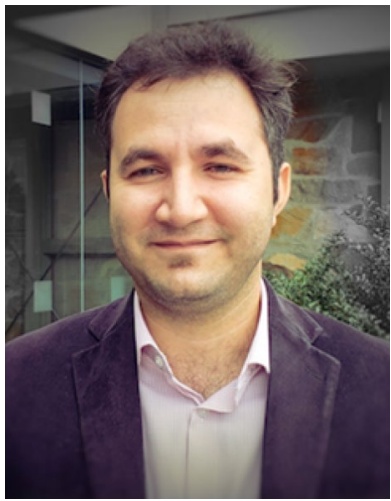

Ahmet E. Akosman currently serves as an assistant professor at Roger Williams University, Bristol RI, USA. He received his $\mathrm{PhD}$ degree in electrical engineering from Boston University. Dr. Akosman's dissertation work focused on the ultrafast pulse dynamics in low noise modelocked fiber lasers. He currently pursues research on the development of novel fiber laser designs and photonic crystal fibers.

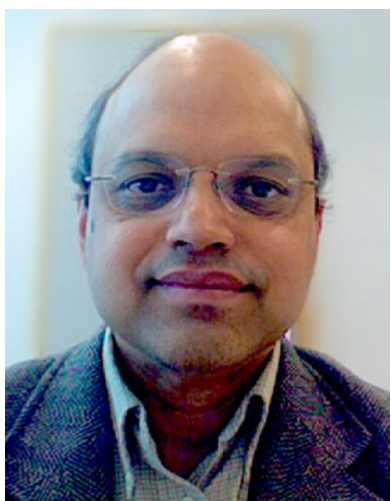

Dr. Shyamsunder Erramilli is a professor in the Department of Physics, Department of Biomedical Engineering, Division of Materials Science and Engineering and a member of the Photonics Center at Boston University. He obtained his Ph.D. in Physics from University of Illinois, Urbana-Champaign, in 1986. He was awarded the DuPont Young Professor Award for 1996. Prof. Erramilli has worked in the field of Biological Physics for nearly thirty years. His research interests are near-field infrared microscopy, ultrafast infrared spectroscopy and mid-IR fibers. He was a co-discoverer of a novel class of solitons in hydrogen-bonded systems, and he was the lead in obtaining the first ever mid-infrared images of single living cells in water, breaking the diffraction limit.

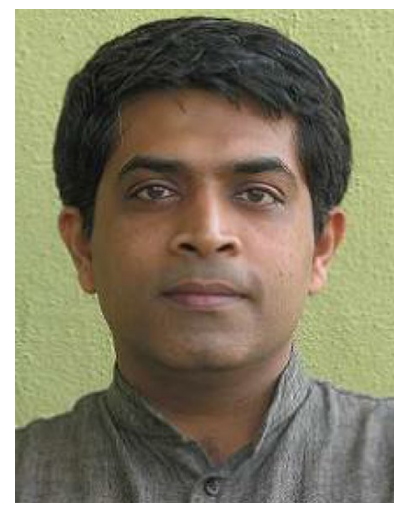

Dr. Siddharth Ramachandran obtained his $\mathrm{PhD}$ in Electrical Engineering from the University of Illinois, Urbana-Champaign, in 1998. Thereafter, he joined Bell Labs as a Member of Technical Staff and subsequently continued with its spin-off, OFS Labs. After a decade in industry, Dr. Ramachandran moved back to academics in 2010, and is now a Professor in the Depts. of Electrical Engineering and Physics, and the Division of Materials Science, at Boston University. Prof. Ramachandran's research focuses on the optical physics of guided waves. For his contributions, he was named a Distinguished Member of Technical Staff at OFS (2003), a fellow of OSA (2010), IEEE (2019) and SPIE (2019), an IEEE Distinguished Lecturer (2013-2015), a Distinguished Visiting Fellow of the UK Royal Society of Engineering (2016), and a Vannevar Bush Faculty Fellow (2019). He serves the optics community in several capacities, including, currently, as a topical editor for Optica.

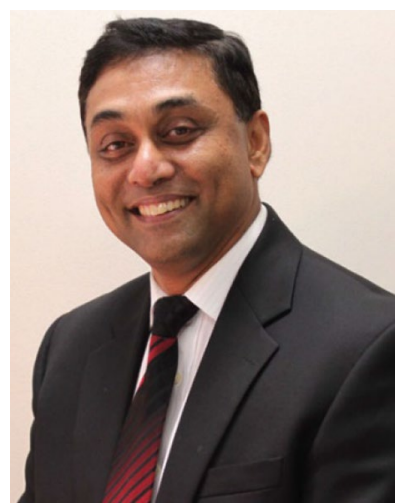

Soumendra N. Basu is Professor and Associate Division Head of Materials Science and Engineering, Professor of Mechanical Engineering, and a member of the Photonics Center at Boston University. After receiving his Ph.D. in Materials Science and Engineering from MIT, Professor Basu was a Postdoctoral Research Associate at Los Alamos National Laboratory, before joining Boston University in 1990. His research interests include processing/structure/ property relationships in materials for energy, photonic and electronic applications. Professor Basu has published more than 150 technical articles, and has been on the Organizing/International Advisory Committees of many international conferences. He is the current Chair of the Energy Conversion and Storage Committee of The Mineral Metals and Materials Society. 